\title{
Resistencia de insectos a cultivos transgénicos con propiedades insecticidas. Teoría, estado del arte y desafíos para la República Argentina
}

Trumper, E.V.

\begin{abstract}
RESUMEN
Los cultivos Bt ejercen alta presión de selección sobre las plagas blanco. Para mitigar la evolución de resistencia, la estrategia Alta Dosis-Refugio (AD-R) requiere: a) una concentración de toxina en la planta suficientemente elevada para provocar que los alelos resistentes sean funcionalmente recesivos; b) baja frecuencia inicial del alelo resistente; c) refugios con plantas no-Bt. Para reforzar la estrategia AD-R, se propone la acumulación de dos o más toxinas en una planta (genes "piramidados"), bajo el supuesto de que estas tienen sitios de acción diferentes, a fin de minimizar el riesgo de resistencia cruzada. Una reciente revisión respalda las fortalezas de la estrategia AD-R en la demora de la evolución de resistencia. El incumplimiento de uno o más componentes de esta estrategia explica los pocos casos de resistencia confirmados. En San Luis, Argentina, se detectaron importantes daños de Diatraea saccharalis en híbridos de maíz Bt. Entre las hipótesis para explicar estos daños, se incluyen dominancia del alelo resistente, baja concentración de toxina y bajo nivel de adopción de refugios. Esto último motiva discusiones sobre la conveniencia de implementar refugios integrados. Se recomienda un abordaje caso por caso para diseñar estrategias de manejo de resistencia de acuerdo a cada plaga.
\end{abstract}

Palabras clave: cultivos Bt, plagas agrícolas, resistencia, herencia, manejo de resistencia de insectos.

Trumper, E.V., 2014. Insect resistance to transgenic crops with insecticidal properties. Theory, state of the art and challenges for Argentina. Agriscientia 31 (2): 109-126

\section{SUMMARY}

Bt crops exert high selective pressure on target pests. To mitigate resistance evolution the High-Dose/Refuge strategy (HDRS) requires: a) toxin expression in plant sufficiently high to render resistance alleles recessive; b) low initial frequency of the resistance allele; c) spatial refuges of non Bt crops. Gene pyramiding, the combination of two or more toxins in a transgenic plant, is proposed to reinforce the HDRS under the assumption of toxins having 
different binding sites to reduce the likelihood of cross-resistance. A recent review supports the strengths of the HDRS in delaying evolution of resistance. Failure to comply one or more of the requirements of the HDRS explains the few cases of confirmed field-evolved resistance. In San Luis, Argentina, significant damage by Diatraea saccharalis was detected in some Bt maize hybrids. Hypotheses to explain these high levels of crop damage, include low level of refuge compliance, dominance of a resistance allele, and low toxin expression. The low level of refuge adoption triggers discussions about the opportunity of promoting seed mixture refuges. A case by case approach is advocated to tailor IRM strategies according to the specific knowledge about the ecology of each pest.

Keywords: Bt crops, agricultural pests, resistance, inheritance, insect resistance management

E.V. Trumper: INTA - EEA Manfredi, Manfredi, Córdoba, Argentina.

Correspondencia a: trumper.eduardo@inta.gob.ar

\section{INTRODUCCIÓN}

\section{El norte en la brújula: el MIP}

Desde su nacimiento, la agricultura ha sido una arena en la que el ser humano ha ejercitado su capacidad de innovación para mejorar sus condiciones de vida a través de mayor producción y/o mejor calidad. Estos dos atributos pueden estar en riesgo en diferentes etapas del ciclo de un cultivo como consecuencia de la influencia de diferentes factores de estrés. Entre ellos, los organismos perjudiciales, y más específicamente los organismos animales invertebrados, han motivado la generación, evaluación, adaptación y consolidación de un amplio abanico de herramientas, técnicas, tácticas y estrategias para hacer frente a estas adversidades biológicas. Ya sea sobre la base de la secuencia inductiva ensayo-error-evaluación-cambio/adopción, aplicada espontáneamente, o a partir de conocimiento generado por aplicación del método científico hipotético-deductivo, a través del tiempo las opciones de manejo fueron articulándose en mayor o menor medida, y fueron insertándose en marcos conceptuales que le confirieron contención, sentido y proyección. Los principios del Manejo Integrado de Plagas (MIP) se pusieron en práctica en el Valle de Cañete, Perú, en la década de 1950, aun antes de que el término se acuñara (Peshin \& Dhawan, 2009). Hacia fines de dicha década, un grupo de entomólogos de la Universidad de California trabajó en la concepción de un enfoque que permitiera la armonización de los factores naturales de control de plagas y el uso de insecticidas de síntesis, lo que desembocó en el artículo fundacional de Stern et al. (1959). Allí se formalizó el concepto de manejo de plagas agrícolas inte- grando criterios bio-económicos de toma de decisiones, en lo que hoy se conoce globalmente como Manejo Integrado de Plagas. Desde entonces y hasta la actualidad, atravesando numerosas extensiones y mejoras de su definición (Trumper, 2009), el MIP ha sido el encuadre discursivo dominante para plantear estrategias de manejo de plagas, las que pocas veces se tradujeron en una implementación real de sus preceptos. No obstante, el MIP ha llegado a constituirse como un término de referencia relevante en el establecimiento de políticas institucionales (Peshin \& Zhang, 2014). Más allá de las diferentes ópticas con las que se puedan interpretar las definiciones de MIP, o las diferencias de énfasis en aspectos específicos, el MIP constituye un punto de referencia sobre cuya base discutir el estatus de las estrategias de manejo de plagas agrícolas impulsadas en un país o región. Tomando las definiciones de mayor ascendente (Kogan, 1998; Mitchel \& Hutchison, 2009; FAO, 2014), se puede entender el MIP como un manifiesto que apela al diseño de sistemas productivos que minimicen la emergencia e incidencia de plagas, y al uso de criterios científicamente fundamentados para la toma de decisiones de manejo preventivo o correctivo, apuntando a minimizar los riesgos económicos, ambientales y sociales.

\section{La resistencia de plagas}

La historia de la agricultura ha demostrado que los artrópodos plaga pueden desarrollar, tarde o temprano y a través de un proceso micro-evolutivo, la capacidad para tolerar las restricciones biológicas de toda táctica de manejo que les imponga una presión selectiva elevada y uniforme por perío- 
dos prolongados de tiempo. La resistencia habilita a los artrópodos a superar las prácticas de control, a través de cambios de comportamiento, de desarrollo o de procesos bioquímicos (Onstad, 2014a). Con cerca de 550 especies de artrópodos plaga (Whalon et al., 2013), la evolución de resistencia es un problema creciente y amenaza la salud pública (Prato et al., 2012) y la agricultura a nivel mundial (Heckel, 2012; Tabashnik et al., 2014).

Entre las herramientas que integran la paleta disponible para diseñar estrategias de manejo de plagas, los cultivos Bt son uno de los que ejercen mayor presión selectiva y, por lo tanto, se encuentra entre los insumos que tienen mayor probabilidad de generar resistencia. La primera consecuencia directa de esta evolución de resistencia es la disminución de su efectividad en el manejo de la plaga blanco. En 2013, la superficie sembrada con cultivos portadores de la toxina Bt (eventos individuales 0 apilados) a nivel mundial llegó a las 75 millones de hectáreas (ISAAA, 2014), mientras que en la Argentina, en la campaña 2012/2013/14, se alcanzaron entre 3,5 y 4 millones ha, representadas principalmente (entre $85 \%$ y $98 \%$, período 2000-2011) por maíz Bt (ArgenBio, 2014). En consecuencia, es claro el impacto que la resistencia puede provocar en la producción. Desde una perspectiva ambiental, la resistencia de plagas representa la erosión de un bien común, un recurso natural no renovable que merece valoración: la susceptibilidad de las plagas a las toxinas $\mathrm{Bt}$ (Bourguet et al., 2005). Los objetivos de esta revisión son: a) presentar el marco conceptual básico que se requiere para comprender el problema de la resistencia; b) sintetizar las principales herramientas que la teoría y la experiencia mundiales respaldan para minimizar el riesgo de evolución de resistencia de plagas a cultivos Bt; y c) comentar el estado de situación a nivel mundial y nacional.

\section{COMPONENTES Y PROCESOS DEL PRO- BLEMA}

El fenómeno de la resistencia involucra componentes y procesos. Los componentes fundamentales son los siguientes: a) un factor de estrés (un insecticida, una toxina, etc.); b) el organismo; c) la población. Esta estructura se completa con la base genética que determina el nivel de susceptibilidad del organismo y su distribución en la población. Por otra parte, la resistencia involucra un proceso esencial que la define: una disminución temporal en la fracción de la población que es susceptible al factor de estrés. A su vez, este proceso sufre la influencia directa e indirecta de numerosos fac- tores relacionados con la genética, la ecología de la(s) plaga(s) blanco, y las prácticas agronómicas. Una cabal comprensión de este sistema, requiere definir, describir y analizar estos diferentes componentes y procesos.

\section{El factor de estrés: Las toxinas Bt}

En el contexto de este artículo, a menos que se especifique lo contrario, el factor de estrés siempre se referirá a una sustancia con propiedades insecticidas incorporada en una planta y el material genético que codifica su síntesis, denominada en forma genérica por la Agencia de Protección Ambiental de los Estados Unidos como PIP, sigla correspondiente a la expresión Plant Incorporated Protectant (USEPA, 2013). Esta definición habilita la inclusión de diferentes sustancias con distintos orígenes (Nelson \& Alves, 2014). Muchas sustancias han sido exploradas como potenciales PIPs. Estas incluyen: a) toxinas producidas por la bacteria Bacillus thuringiensis; b) el complejo de proteínas tóxicas producidas por las bacterias Photorhabdus luminescens y Xenorhabdus nematophyla; c) sustancias vegetales inhibidoras de proteasas de insectos que comprometen su nutrición; d) enzimas proteolíticas de origen vegetal o viral cuyo blanco pueden ser nutrientes críticos del insecto, enzimas metabólicas o proteínas que forman parte de estructuras vitales en el insecto; e) lectinas, proteínas que pueden afectar el reconocimiento intercelular o provocar aglutinaciones celulares deletéreas (Nelson \& Alves, 2014). Actualmente las únicas PIPs disponibles en cultivos habilitados comercialmente, son las provenientes de Bacillus thuringiensis, una bacteria aeróbica, Gram positiva, formadora de esporas (Pigott et al., 2008), hallada comúnmente en el suelo en todo el mundo y conocida por su capacidad de producir dos tipos de toxinas con actividad insecticida específica: 1) inclusiones parasporales de cristales proteicos (van Frankenhuyzen, 2009), conocidos como proteínas Cry (Bravo et al., 2012); 2) proteínas conocidas como Vip (Vegetative Insecticidal Protein) (Yu et al., 2011).

El ciclo de vida de $B$. thuringiensis se divide en cuatro fases. Durante la primera, llamada fase vegetativa, ocurre crecimiento y división cuando las condiciones ambientales son favorables. La fase II es de transición a la esporulación; la fase III es de esporulación propiamente dicha y la fase IV implica la maduración de las esporas y la lisis celular (George \& Crickmore, 2012). El ingreso a la fase de esporulación se ha asociado a señales de restricción de nutrientes (Nelson \& Alves, 2014), o alta densi- 
dad celular y progresión del ciclo celular (George \& Crickmore, 2012). Durante la fase vegetativa, $B$. thuringiensis produce y secreta las proteínas Vip, que expresan actividad insecticida contra lepidópteros, coleópteros y algunas especies de insectos picadores-chupadores (Palma et al., 2012). De estas proteínas se han identificado más de 82 genes diferentes (Yu et al., 2011) agrupados en cuatro clases o familias. Vip1 y Vip2 actúan en forma combinada como toxinas binarias, con reportes de actividad específica sobre larvas de algunas especies de coleópteros. La clase Vip 3 ha evidenciado una actividad de amplio espectro sobre larvas de lepidópteros (Ruiz de Escudero et al., 2014), y se divide en dos subfamilias, Vip3A y Vip3B. Las proteínas Vip3A tienen receptores en las células de las membranas del epitelio intestinal del insecto blanco diferentes a las de las proteínas Cry, lo que además de concitar la atención de los investigadores para ampliar el espectro de plagas blanco de bioinsecticidas a base de $\mathrm{Bt}$, las convierte en una interesante opción para complementar a las proteínas Cry en estrategias de manejo de la resistencia (Palma et al., 2012; Ruiz de Escudero et al., 2014).

Cuando $B$. thuringiensis ingresa en su fase de esporulación, la bacteria produce esporas y grandes inclusiones cristalinas cuyo principal componente son las proteínas Cry (Pigott et al., 2008; Nelson \& Alves, 2014). Las proteínas Cry comprenden una amplia familia de toxinas con diversas especificidades. La mayoría son tóxicas para lepidópteros, dípteros y coleópteros, pero algunas han evidenciado efectos sobre himenópteros y nematodos (Pigott et al., 2008). Las proteínas Cry se consideran protoxinas que se activan cuando son ingeridas por un insecto (Heckel et al., 2007), y junto a otros factores de virulencia debilitan o provocan la muerte del insecto, lo que permite la germinación de las esporas bacterianas en el insecto y contribuye a la propagación de la siguiente generación. En el caso específico de lepidópteros, el proceso comienza cuando el alto pH del intestino medio de la larva provoca la solubilización de los cristales y la liberación de las protoxinas sobre cuyos sitios de clivaje expuestos actúan proteasas que liberan el núcleo activo de la proteína (la toxina). Luego estas toxinas se ligan a receptores específicos en la superficie del epitelio intestinal de la larva, provocando la formación de poros y con ello la ruptura de las membranas celulares y finalmente la muerte del hospedante (Heckel et al., 2007; Pigott et al., 2008; Pardo-López et al., 2013; Gómez et al., 2014). Las inclusiones cristalinas pueden contener diferentes tipos de protoxinas, lo que determina perfiles de toxicidad de las diferentes cepas (Pigott \& Ellar, 2007).

\section{El individuo}

Cada individuo de una determinada especie de plaga blanco, dependiendo de su susceptibilidad al factor de estrés, sufre o no un efecto deletéreo que compromete la culminación de su ciclo y su reproducción. La susceptibilidad de un individuo a una toxina está determinada por la susceptibilidad inherente de la especie a la que pertenece, es decir tiene un componente genético específico. Recientemente, Han et al. (2014) encontraron evidencias de una relación estrecha entre el nivel de susceptibilidad y la concentración de sitios activos o sitios de ligadura. Un insecto, bajo determinadas condiciones fisiológicas y ambientales, o es susceptible o es tolerante. Esta respuesta de un individuo clasificada en dos categorías (afectado Vs. no afectado), es una simplificación, habida cuenta de las respuestas intermedias que se han observado. Por otra parte, es necesario distinguir la edad y/o estado de desarrollo del insecto, ya que, por ejemplo, en larvas de lepidópteros se conoce que los diferentes estadios tienen diferentes niveles de susceptibilidad (Huang et al., 1999; 2002; 2006).

Es recomendable tener en cuenta algunas sutilezas en los términos que se emplean para evitar confusiones de interpretación. Al nivel individual el término susceptibilidad puede hacer referencia a una respuesta categórica de tipo todo o nada (muere o no muere). Así, ante un determinado escenario de exposición a una toxina, un insecto no muere, pero si el escenario de exposición a la toxina es diferente, ese mismo individuo tiene la potencialidad de mostrar la respuesta opuesta. Otro modo de emplear el término susceptibilidad es fijando la perspectiva desde la toxina, haciendo referencia a la concentración con la cual un individuo muere. Para esta segunda acepción de susceptibilidad, existe un término complementario que tiene mayor entidad formal: la tolerancia. Tomando la recomendación de Tabashnik et al. (2014), tolerancia se define como "la más alta concentración de un plaguicida en particular que un individuo puede soportar sin ser eliminado". Integrando las dos acepciones, un insecto es susceptible (si muere al exponerlo a una toxina) y tiene una determinada susceptibilidad cuantificable (la concentración de toxina frente a la cual muere).

\section{La población}

Como se señaló en el apartado anterior, un individuo puede ser considerado o no susceptible. Sin embargo una población no se categoriza como fenotípicamente susceptible. En efecto, una po- 
blación de insectos de una determinada especie blanco presenta una distribución de susceptibilidades a un determinado factor de estrés (la toxina Bt) como consecuencia de la variabilidad que generan las diferentes condiciones fisiológicas y ambientales que experimentan los individuos que componen la población. Además, aun bajo las mismas condiciones ambientales, cabe esperar, y de hecho se conocen, variaciones intra-poblacionales. En el contexto de la evolución de resistencia a plaguicidas, algunos investigadores plantean que con anterioridad a la exposición de la población a un determinado ingrediente activo, ésta consiste de fenotipos que si bien son genotípicamente susceptibles, presentan una distribución de viabilidades. Esta distribución suele ser normal, lo que sugiere que muchos factores, tanto ambientales como genéticos, determinan los fenotipos resistentes de una población (Roush \& McKenzie, 1987; MacNair, 1991; MacKenzie \& Batterham, 1994).

\section{La resistencia}

Si bien el significado del término "resistencia" puede parecer obvio en un plano de discusión general, el ejercicio de un análisis más profundo revela detalles y matices de su empleo en los distintos ámbitos (academia, industria, extensión), que ha merecido el enunciado de definiciones precisas y específicas del término, algunas complementarias entre sí, otras con cierto grado de contradicción aparente. Asimismo, fue necesario acuñar algunas expresiones nuevas para dar cuenta de procesos involucrados, introduciendo la idea de cambio. En lugar de citar las diferentes definiciones enfrentando al lector a la elección de aquella que pueda resultarle más convincente, en este artículo se propone una síntesis que integra los aspectos compatibles de las versiones propuestas por Roush (1998), Andow (2008), Tabashnik et al. (2009; 2014) y Carrière et al. (2010), entre otros. No obstante, se recomienda al lector la precaución de identificar con claridad el criterio sobre cuya base se emplean los términos específicos en la literatura consultada.

En el contexto de este artículo, la resistencia es el carácter heredable consistente en la menor susceptibilidad (fenotipo) de un insecto (individuo) a la toxina $\mathrm{Bt}$ en relación a individuos de la misma población. Crava et al. (2013) complementan este concepto refiriendo a la tolerancia como una medida cuantitativa de la resistencia que está distribuida entre los individuos de una población. Al definir a la resistencia como un carácter heredable, cabe considerar el genotipo que lo determina y su frecuencia en la población, la que frente a la presión de selección que ejerce el insecticida, crecerá en el tiempo (Caprio et al., 2008). La resistencia de campo a una toxina $\mathrm{Bt}$ (field-evolved resistance en la literatura internacional vigente) es la menor susceptibilidad de una población de insectos como consecuencia de la exposición a esa toxina a campo, en relación a la línea base de susceptibilidad, a su vez definida como la $\mathrm{CL}_{50}$ (concentración de una toxina que provoca la muerte del 50\% de la población) de la toxina Bt en poblaciones de diferentes regiones previa a la introducción de la toxina (por ejemplo, Bernardi et al., 2012). Cabe aclarar que si bien la expresión "línea base de susceptibilidad" es ampliamente utilizada, Tabashnik et al. (2014) proponen referirse a susceptibilidad inherente, expresión más acorde al concepto involucrado. Con estas definiciones, para cerrar un grupo básico de términos de referencia sólo resta agregar que la evolución de resistencia de campo a una toxina Bt es el proceso de selección natural (Heckel, 2012) que provoca una disminución de la susceptibilidad (a la toxina Bt) en una población a campo.

\section{Caracterización de la susceptibilidad}

La susceptibilidad a la toxina es el carácter sujeto a evolución por selección natural. La susceptibilidad es la tendencia de un insecto a ser afectado por una toxina (Tabashnik et al., 2014). En una primera aproximación, puede pensarse que el efecto es categórico: el insecto muere o sobrevive. Esta categorización simplifica la realidad, ya que se han observado respuestas intermedias. Así, por ejemplo, es frecuente que las larvas de lepidópteros expuestas a una determinada concentración de toxina Bt manifiesten una respuesta de inhibición de crecimiento que se traduce en disminución de la tasa de desarrollo y/o reducción de tamaño, que puede o no desembocar en la muerte antes de completar el desarrollo (Juan Carlos Gamundi, 2014, comunicación personal). Coincidentemente, Tabashnik et al. (2014) incluyen el parámetro IC50 que refiere a la concentración que provoca la inhibición del crecimiento del $50 \%$ de los individuos de una población.

Pero la razón de mayor peso para considerar que la susceptibilidad no es un carácter categórico, es el hecho de que típicamente se presenta como una distribución de viabilidades (MacKenzie \& Batterham, 1994). En una población, la susceptibilidad es una variable continua con una distribución unimodal, generalmente normal, tal que al incrementar la concentración de la toxina (variable 
independiente) dentro de un determinado rango, el porcentaje de mortalidad (variable respuesta) se incrementa siguiendo una curva sigmoidea conocida como curva dosis-respuesta. La descripción estadística de esta relación se representa expresando la mortalidad en unidades probit, en función del logaritmo de la concentración de toxina (McCallum, 2000; Ferré et al., 2008), como se ilustra esquemáticamente en la Figura 1. La escala probit expresa probabilidades y abarca valores equivalentes al rango desde la mínima ( 0\%) hasta la máxima (100\%) mortalidad. De este modo, se puede evaluar la función con diferentes valores de concentración de toxina para hallar la probabilidad de muerte o efecto deletéreo. Asimismo, se puede emplear esta función para estimar parámetros como CL50, CL95, etc., y permite identificar con claridad todo el rango de concentración de toxina que abarca la variación de respuesta (mortalidad) de la población ( $R$ en la Fig. 1).

Dos poblaciones homogéneas, $A$ y $B$, ya sea de diferentes especies o bien de la misma especie pero con bajo o nulo intercambio genético entre sí, pueden tener susceptibilidades inherentes distintas para una misma toxina. Por lo tanto, cada una de ellas tendrá una relación concentración-mortalidad diferente. De este modo, una misma concentración de toxina puede asociarse a diferentes probabilidades de mortalidad en esas distintas poblaciones (Figura 2).

En este apartado se ha descripto el carácter sobre el cual operará la selección natural cuando la población se encuentre en un escenario de presión selectiva, como lo es la siembra de un cultivo que expresa en forma continua una toxina Bt. Cabe enfatizar, como corolario, que este rasgo fenotípico no es categórico sino que, aun antes de su expo-

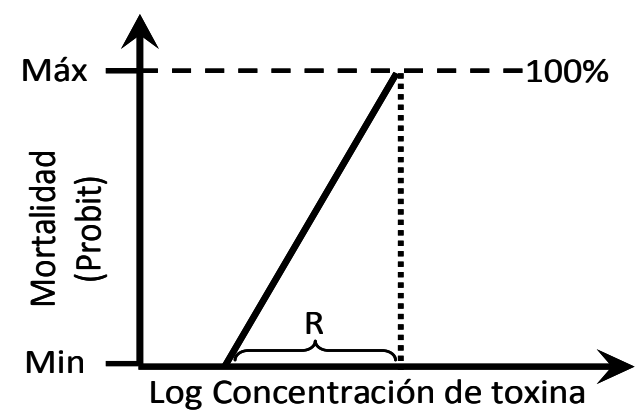

Fig. 1. Ilustración esquemática del modelo probit de la mortalidad en función del logaritmo de la concentración de una toxina. R: rango de concentración de toxina que abarca la variabilidad poblacional. sición a la toxina, la población presenta una considerable variación en la susceptibilidad/tolerancia.

\section{El salto genético hacia la resistencia}

La variación fenotípica continua de la tolerancia dentro de una población homogénea se asocia a una diferenciación poligénica entre sus individuos (MacKenzie \& Batterham, 1994). Diferentes autores sostienen un modelo conceptual postulando, entre otros aspectos, que la alta presión de selección a la que se someten las poblaciones de plagas bajo regímenes de control mediante insecticidas o toxinas $\mathrm{Bt}$, favorece la evolución de resistencia a campo de alelos de efecto mayor (MacNair, 1991; Groeters \& Tabashnik, 2000; Carrière et al., 2010). Los llamados genes de efecto mayor son aquellos que confieren un cambio substancial en el carácter, en este caso la susceptibilidad. Particularmente en el caso de poblaciones con una alta susceptibilidad inherente a la toxina, las mutaciones que confieren una pequeña disminución de la susceptibilidad sólo determinarán ventajas adaptativas mínimas (Carriére et al., 2010). En los insectos, para la evolución de resistencia a campo, el cambio de susceptibilidad es crítico cuando está determinado por el cambio en un gen individual (un locus) que provoca un salto en la susceptibilidad dentro de una población (MacKenzie \& Batterham, 1994). Efectivamente, aunque algunos estudios indican la posibilidad de que en las poblaciones de insectos surjan dos o más genes involucrados en la resistencia a una toxina Bt, la mayoría de los modelos teóricos que describen la evolución de resistencia se han desarrollado sobre la base de una herencia monogénica (Ferré \& Van Rie, 2002).

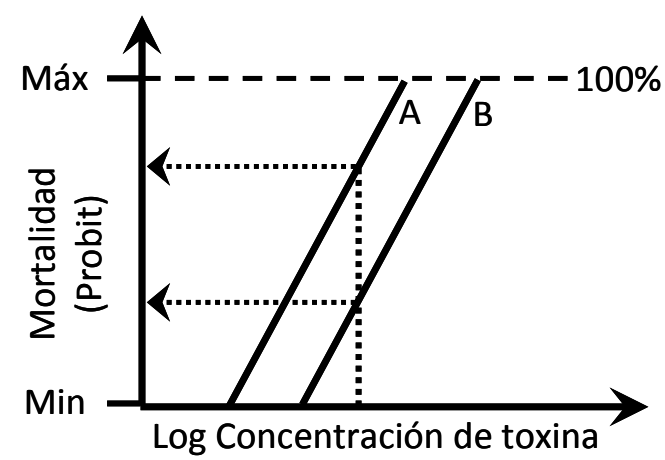

Fig. 2. Modelo probit de la mortalidad en función del logaritmo de la concentración de una toxina para dos poblaciones homogéneas, A y B, cada una con su correspondiente susceptibilidad inherente. Una misma concentración de toxina determina diferentes probabilidades de muerte. 


\section{Mecanismo monogénico de herencia de la resistencia}

Asumiendo que un solo gen dialélico está involucrado en la evolución de resistencia, los genotipos posibles son homocigota susceptible (SS), heterocigota (RS) y homocigota resistente (RR). Por lo general, se asume que el alelo de resistencia $(R)$ es recesivo, supuesto que descansa en diversos estudios, principalmente de laboratorio (Campagne et al., 2013). Asimismo, un mecanismo de resistencia a toxinas Bt frecuentemente citado, llamado resistencia de modo 1, involucra la ligadura de las toxinas al epitelio del intestino medio (Ferré et al., 2008), lo que se espera resulte en una herencia intrínsecamente recesiva (Tabashnik et al., 1998). La mayor parte de los casos de resistencia estudiados tiene un modo de herencia que no resulta completamente recesivo (Ferré \& Van Rie, 2002). Por ejemplo, se ha encontrado herencia dominante en Busseaola fusca (Campagne et al., 2013), semidominante en Helicoverpa armigera (Nair et al., 2010) y dominancia incompleta en H. zea (Tabashnik et al., 2008). Estos ejemplos constituyen casos particulares en un rango de dominancia, cuyos extremos son las herencias recesiva y dominante completas. La dominancia genética es el grado en el cual el fenotipo de un individuo con genotipo heterocigota se asemeja al fenotipo de un individuo de genotipo homocigota con el cual coincide en un alelo. En el caso de caracteres determinados por un solo locus, un alelo A es dominante sobre otro, a, cuando su expresión determina la respuesta (el fenotipo) del genotipo heterocigota, Aa (Onstad \& Gassmann, 2014).

La dominancia de la resistencia a insecticidas y toxinas Bt no es una propiedad genética constante. Por ejemplo, en el caso particular de la resistencia determinada por mutaciones que provocan una disminución de la afinidad a los sitios de acción, los mecanismos identificados varían desde recesividad completa hasta dominancia completa (Bourguet \& Raymond, 1998). Por otra parte, la dominancia depende del ambiente, especialmente la concentración de la toxina (Roush \& Daly, 1990; Bourguet et al., 2000). La combinación entre el nivel de expresión del alelo de resistencia y la concentración de la toxina determina un rango de variación fenotípica. Para cada uno de los tres posibles genotipos se puede establecer la función concentración-mortalidad; la Figura 3.a las representa para los dos genotipos homocigotas, SS y RR. Como puede observarse, la relación concentración-mortalidad para estos dos genotipos es bien contrastante. La menor concentración de toxina elimina el $100 \%$ de los individuos SS y no ejerce ningún efecto sobre los RR. Es necesario incre- mentar considerablemente la concentración para provocar la mortalidad de una pequeña fracción de los homocigotas resistentes. Cabe destacar con este ejemplo hipotético, que en un conjunto de individuos con genotipo homocigota resistente, parte de ellos, ante una determinada concentración de toxina, puede manifestarse como un fenotipo susceptible. En cuanto al genotipo heterocigota, sus fenotipos pueden revelarse con una gama de respuestas concentración-mortalidad (Ferré et al., 2008). El la Figura 3.b se representan cinco respuestas en todo el rango que va desde la herencia completamente recesiva $\left(\mathrm{RS}_{1}\right)$ hasta completamente dominante $\left(\mathrm{RS}_{5}\right)$. Como puede observarse al contrastar los dos esquemas, A y B, de la Fig. 3, el fenotipo de RS, es igual al de SS, mientras que el fenotipo de $\mathrm{RS}_{5}$ es el mismo que el fenotipo de RR. Los casos intermedios corresponden a mecanismos de herencia de la resistencia incompletamente recesivo $\left(R_{2}\right)$, codominante $\left(R_{3}\right)$ e incompletamente dominante $\left(\mathrm{RS}_{4}\right)$, respectivamente. Por otra parte, el fenotipo de un heterocigota depende de la concentración de la toxina. Ante una concentración baja, con el genotipo $\mathrm{RS}_{3}$ la resistencia resulta funcionalmente dominante, mientras que frente a una concentración alta la resistencia es funcionalmente recesiva (Fig. 3.b). Así, como corolario, se puede decir que a mayor concentración de toxina, menor es el nivel de dominancia del alelo resistente (Tabashnik et al., 2004).

Habida cuenta de su influencia sobre la herencia de la resistencia, todos aquellos factores que influyen en la concentración de la toxina merecen atención. La variación de la concentración de toxina ocurre naturalmente, pero también puede constituir un criterio de selección de eventos Bt en la etapa de desarrollo. Debido a que la concentración de la toxina puede variar en los tejidos de la planta transgénica a través de su desarrollo fenológico, o bajo diferentes condiciones ambientales, la dominancia, y por lo tanto la intensidad de la selección en las plagas blanco, son condiciones dinámicas (Onstad \& Gassman, 2014). Por ejemplo, la tolerancia de los insectos disminuye sustancialmente en etapas reproductivas tempranas en plantas de arroz que no reciben fertilización nitrogenada e incluso en floración, aun en plantas con adecuado suministro de nitrógeno (Alinia et al., 2000). Durante la fase de maduración del algodón, la reasignación del nitrógeno de la planta hacia la producción de órganos reproductivos provoca la disminución de la concentración de toxina durante prolongados períodos (Olsen et al., 2005). La variación de la concentración de toxina Bt puede tener consecuencias negativas. Por ejemplo, Onstad \& Gould (1998) sostienen que en muchas circunstancias la 
evolución de resistencia fue mayor porque la disminución de la concentración de la toxina favoreció a los individuos heterogocigotas en la población plaga, situación que se ve reflejada en la Fig. 3.b. Si se analiza el genotipo $\mathrm{RS}_{3}$, cuyo fenotipo es de dominancia intermedia, la disminución de la concentración de toxina de alta a baja, determina un cambio de $0 \%$ a casi $100 \%$ de supervivencia, contribuyendo a mantener o incrementar la frecuencia del alelo resistencia.
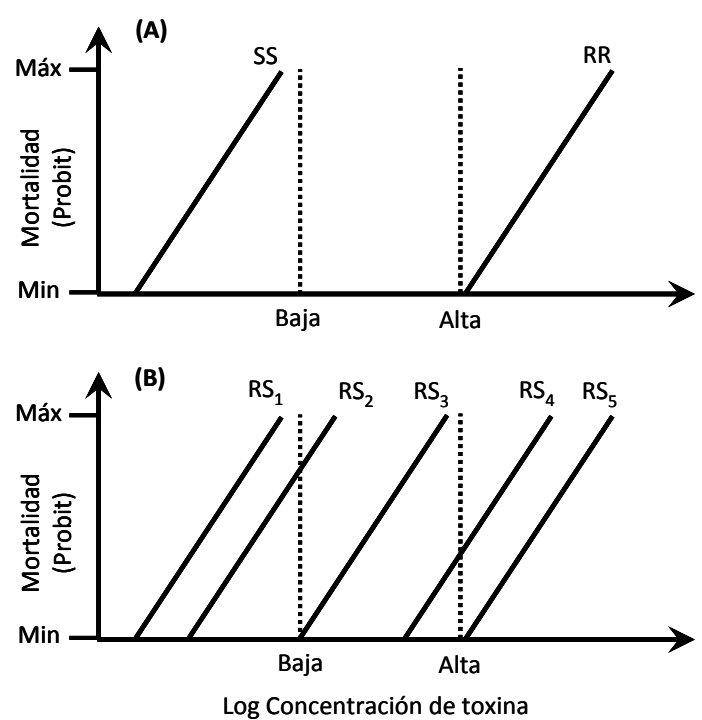

Fig. 3. Función concentración-mortalidad específica para diferentes genotipos. A) Homocigotas susceptible (SS) y resistente (RR). B) Cinco diferentes fenotipos del genotipo heterocigota: completamente recesivo $\left(\mathrm{RS}_{1}\right)$; incompletamente recesivo $\left(\mathrm{RS}_{2}\right)$; codominante $\left(\mathrm{RS}_{3}\right)$; incompletamente dominante (RS $)$; completamente dominante (RS $)_{5}$. Se señalan dos concentraciones hipotéticas, alta y baja, determinando cambios en la expresión fenotípica del genotipo heterocigota.

\section{ESTRATEGIA DE MANEJO DE LA RESIS- TENCIA}

La evolución de resistencia de insectos plaga a tácticas de control, especialmente las que involucran el empleo de insecticidas de aplicación o toxinas incorporadas en cultivos transgénicos, es considerada por muchos autores como un proceso inevitable (Bates et al., 2005; Fitt et al., 2006; Head \& Greenplate, 2012). Esta afirmación descansa en el supuesto de un patrón geográfico e intensidad de adopción de la táctica de control tales que determinan una tasa de evolución de resistencia superior a la contención posible mediante estrategias para su manejo. Evidentemente, cuando adopción, implementación y manejo confluyen en una alta presión de selección, la evolución de resistencia es inevitable. Es éste el escenario en el que se apoyan las afirmaciones de inexorabilidad de la evolución de resistencia de los representantes de la industria y de muchos investigadores. Pero es oportuno recordar que esta posición implica un desvío de los preceptos del MIP, al naturalizar desde un principio las condiciones que determinan el carácter inevitable de la evolución de resistencia.

El objetivo del manejo de la resistencia es prevenir o demorar la evolución de resistencia a campo y el propósito es disminuir los riesgos de fallas de control de las plagas blanco (Andow, 2008; Head $\&$ Greenplate, 2012). Aunque se puede conocer, estimar, o simular el efecto de determinados factores en la tasa de evolución de resistencia, sólo es posible actuar o tener influencia sobre algunos de ellos. La resistencia a plaguicidas condujo al desarrollo de modelos teóricos para identificar y caracterizar la influencia de los principales factores incidentes en la evolución de resistencia y para diseñar estrategias de manejo de la resistencia y para predecir su eficiencia (REX Consortium, 2010; Kang et al., 2014; Onstad, 2014b).

\section{Estrategia alta dosis - refugio}

Una estrategia de manejo de resistencia requiere entender el proceso de evolución de la resistencia. El estudio de la evolución de resistencia a insecticidas y toxinas Bt se ha apoyado principalmente en la teoría de genética poblacional enfocando el determinismo genético y modos de herencia de la resistencia (REX Consortium, 2010). La estrategia mundialmente aceptada para disminuir la tasa de evolución de resistencia se conoce como alta dosis-refugio (AD-R), y se apoya en supuestos (Andow 2008; Huang et al., 2011; Siegfried et al., 2014) acerca del efecto de algunos de aquellos factores, mientras que para los que pueden ser determinados por el desarrollo biotecnológico o las prácticas agronómicas, prescribe determinados estándares a cumplir. Los principios fundamentales en los que se apoya la estrategia AD-R son la reducción de la dominancia y la heredabilidad de la resistencia (Tabashnik et al., 2004). A continuación se describen los supuestos y requisitos de la estrategia AD-R.

\section{Alta dosis}

Bajo el supuesto de una muy baja frecuencia del alelo de resistencia previa a la introducción del cultivo Bt, cabe esperar que los individuos homocigotas resistentes sean extremadamente raros y, por lo tanto, la evolución de resistencia está determinada principalmente o exclusivamente por la frecuencia 
y la supervivencia de los individuos heterocigotas (Bates et al., 2005). Andow (2008) define a la alta dosis como la concentración de toxina a la cual la resistencia se hereda como un alelo recesivo o casi recesivo, de tal modo que los individuos heterocigotas (RS) serán casi tan susceptibles como los individuos homocigotas susceptibles (SS). En una definición operativa, se considera que el evento Bt es de alta dosis cuando el cultivo expresa una concentración de toxina Bt que elimina 99,99\% de la fracción homocigota de la(s) plaga(s) blanco respecto al carácter de susceptibilidad a la toxina, y a la vez provoca la mortalidad de un muy elevado porcentaje ( $\geq 95 \%$ según Huang et al., 2011) de la fracción heterocigota para el mismo carácter.

\section{Herencia recesiva}

El carácter de resistencia de la plaga es recesivo, de modo tal que los individuos heterocigotas deben ser eliminados por la toxina Bt. De este modo, solo los individuos homocigotas resistentes deberían completar su ciclo en una planta $\mathrm{Bt}(\mathrm{Ba}-$ tes et al., 2005; Bourguet et al., 2005). En este punto, debe quedar clara la estrecha vinculación entre este supuesto y el de alta dosis. En efecto, como se explicara en el apartado "Mecanismo monogénico de herencia de la resistencia", el nivel de dominancia está determinado por la tolerancia que confiere el alelo de resistencia y por la concentración de la toxina (Ferré et al., 2008). Cuando el alelo de resistencia es completamente dominante, la influencia de la concentración de toxina es secundaria.

\section{Frecuencia inicial del alelo de resistencia}

La estrategia AD-R requiere que antes de la introducción del cultivo Bt, en la población natural de la plaga blanco, la proporción de individuos con genotipo resistente sea muy baja, en el orden de 10-3 y preferentemente menor (Roush, 1994; Bourguet et al., 2005). Cuando tal requisito se cumple, la mayor parte de los descendientes serán heterocigotas, y en consecuencia, frente a un evento que cumple el requisito de alta dosis, un muy elevado porcentaje de éstos será eliminado (Huang et al., 2011).

\section{Refugio}

El supuesto mencionado anteriormente respecto a una baja frecuencia inicial del alelo de resistencia implica a su vez que al momento de incorporar un cultivo Bt la población plaga tiene una baja frecuencia de individuos heterocigotas. El requisito de alta dosis apunta a provocar al menos 95\% de mortalidad de los heterocigotas. El 5\% restante puede sobrevivir (fenotípicamente resistentes) y al emerger los adultos pueden aparearse entre sí. En cruzamientos de individuos heterocigotas, se espera que $25 \%$ de la descendencia resulte homocigota resistente, $25 \%$ homocigota susceptible y $50 \%$ heterocigota. A excepción de casos singulares de muy alta concentración de toxina y baja susceptibilidad inherente de la plaga blanco, la supervivencia de los individuos homocigotas resistentes no está comprometida por la toxina Bt. En tanto, del $50 \%$ de los heterocigotas, sólo el 5\% sobreviviría, como consecuencia de la alta dosis. De este modo, de cada 100 insectos de la descendencia F1 de un cruzamiento RSxRS emergente de un cultivo Bt, sobreviviría un promedio de 27,5 insectos, 25 correspondientes al genotipo RR y 2,5 $(50 \% \times 5 \%)$ al genotipo RS. Esta supervivencia de casi $30 \%$ de insectos portadores del gen de resistencia, contribuiría a una rápida evolución de la resistencia a campo.

A los efectos disminuir la probabilidad de generación de heterocigotas en la $F 1$, es preciso minimizar la probabilidad de cruzamientos entre heterocigotas. Para lograrlo, surge la necesidad de ofrecer una fuente de generación de individuos homocigotas susceptibles. La implementación de un refugio espacial de cultivo convencional y/o hospedadores alternativos sin el gen Bt, disminuye sensiblemente la probabilidad de apareamiento de adultos portadores del alelo resistente. De este modo, la descendencia mayoritariamente heterocigota es eliminada por la toxina Bt (Andow, 2008). Este supuesto se conoce como efecto dilución (Bates et al., 2005). El objetivo es que la mayor parte de los heterocigotas que sobreviven en el cultivo Bt se apareen con adultos susceptibles que emergen del refugio. De un cruzamiento RSxSS, la descendencia sería 50\% RS (de los cuales se espera sobreviva no más de $5 \%$ ) y $50 \%$ SS (sin posibilidad de sobrevivir en el cultivo Bt). Entonces, de cada 100 insectos de la descendencia F1 de este cruzamiento, sobrevivirían en el cultivo Bt un promedio de $2,5(50 \% \times 5 \%)$ individuos con genotipo RS.

Este contraste entre presencia o ausencia de refugios (y por consiguiente, de individuos SS) es deliberadamente simplificado a los efectos de facilitar la comprensión del concepto detrás de la estrategia. Sin embargo, debe considerarse que para lograr una maximización del apareamiento de los individuos RS emergentes del cultivo Bt con los individuos SS del refugio, deben cumplirse algunas condiciones, de las cuales las más importantes son las siguientes. La primera es que la abundancia de 
individuos SS debe ser muy elevada en relación a los RS que emergen del cultivo Bt. Esto implica que el refugio debe cubrir un área lo suficientemente grande como para que, con los niveles de densidad que la plaga normalmente presenta, el refugio sostenga una población elevada de insectos susceptibles. La segunda condición es que los adultos susceptibles deben estar lo suficientemente cerca de los adultos heterocigotas en relación a su capacidad de dispersión, lo que determina un requisito de proximidad del refugio, específico para cada plaga blanco, dependiendo de su comportamiento de dispersión. Entonces, el efecto dilución opera mediante la maximización del apareamiento entre los adultos heterocigotas fenotípicamente resistentes que emergen del cultivo $\mathrm{Bt}$, y los adultos susceptibles que emergen del refugio.

En general, la decisión acerca del tamaño del refugio que se recomienda o exige en los planes de manejo de la resistencia, se nutre de las proyecciones de tasas de evolución de resistencia que arrojan modelos de simulación. Estas decisiones que se toman en los organismos regulatorios, no siempre se apoyan exclusivamente en los resultados de la investigación, sino que a veces están influidas por instancias de integración de otros criterios (económicos, sociales, de factibilidad).

\section{La táctica de las pirámides}

La estrategia AD-R descripta anteriormente constituye el marco general apoyado en la teoría. Para complementar esta estrategia AD-R se ha propuesto la incorporación conjunta de dos o más genes Bt para una determinada plaga blanco, en una misma variedad. Desde la perspectiva del manejo de la resistencia de insectos a cultivos $\mathrm{Bt}$, se apunta a introducir en estas nuevas variedades al menos dos toxinas Bt, cada una confiriendo alta toxicidad (Ives et al., 2011) con diferentes modos de acción para una misma plaga blanco, a los efectos de evitar la resistencia cruzada a las distintas toxinas. De este modo se asume que la resistencia puede estar gobernada por dos genes di-alélicos, escenario en el cual la resistencia completa requeriría que los insectos tuviesen alelos de resistencia recesivos en cada locus (Tabashnik et al., 2004). Frecuentemente, en la literatura específica, este enfoque se presenta como una estrategia (Roush, 1998; Manyangarirwa et al., 2006; Carrière et al., 2010; Brévault et al., 2013). Sin embargo, considerando que el marco que le confiere sentido sigue siendo la estrategia AD-R, es conveniente referirse a la acumulación de eventos de igual plaga blanco, como una táctica.
El supuesto subyacente de esta táctica es que los diferentes modos de acción implican receptores diferentes en la membrana celular del epitelio intestinal de las larvas (Ferré et al., 2008), y que los genes de resistencia segregan independientemente. En consecuencia, la probabilidad de que un insecto de la población blanco sea portador de un genotipo resistente a las toxinas Bt incorporadas en una misma planta es extremadamente baja (Tabashnik et al., 2013). En efecto, asumiendo baja frecuencia inicial del alelo de resistencia (ver estrategia AD-R), y aplicándolo para los dos genes de una "variedad piramidada", si la frecuencia inicial es $10^{-3}$ para ambos genes, la frecuencia del genotipo doblemente resistente es de $10^{-12}$ (Gould, 1998). Es oportuno reiterar que esta bajísima probabilidad de doble resistencia descansa en el supuesto de independencia de los mecanismos de resistencia de ambos genes. No obstante, el hallazgo de algunos casos de resistencia cruzada (Jackson et al., 2007; Hernández-Rodríguez et al., 2013) y el continuo descubrimiento de nuevos mecanismos involucrados en la resistencia a las toxinas Bt (Jurat-Fuentes et al., 2011; Campagne et al., 2013; Hernández-Rodríguez et al., 2013), en algunos casos hacen dudar de la generalidad de este principio (Tabashnik et al., 2013).

El uso de eventos piramidados probablemente constituya una mejor contribución a la minimización de la tasa de evolución de resistencia. Sin embargo, esta ventaja depende de algunas condiciones. Un supuesto clave para el éxito es el cumplimiento del principio de letalidad redundante (Brévault et al., 2013), según el cual cada toxina del conjunto provoca per se alta mortalidad en los insectos homocigotos susceptibles (Storer et al., 2012). Desde otro ángulo, Showalter et al. (2009) expresan que existe letalidad redundante cuando los insectos con alelos resistentes son eliminados en variedades piramidadas, en tanto y en cuanto porten un alelo susceptible en uno de los loci involucrados. Sobre la base de los aportes de Gould (1986) y Roush (1998), Brévault et al. (2013) sintetizan este concepto expresando que los insectos resistentes a una de las toxinas serán eliminados por la(s) toxina(s) restante(s). A modo de ejemplo, considérese el siguiente caso hipotético de dos toxinas piramidadas, A y B. Asumiendo que la resistencia a cada toxina es recesiva, los insectos con genotipos $R_{A} R_{A}, S_{B} R_{B}$ y $S_{A} R_{A}, R_{B} R_{B}$ sobrevivirían en plantas que produjeran individualmente las toxinas $A$ y $B$, respectivamente. Sin embargo, estos mismos insectos serían eliminados en plantas que produjeran las dos toxinas (Showalter et al., 2009).

La letalidad redundante no es un rasgo categórico, sino que puede cuantificarse. Para tal fin, 
Brévault et al., (2013) propusieron el factor de letalidad redundante (FLR), que se calcula mediante la siguiente ecuación

$$
F L R=1-\left(W_{R_{A} R_{A} S_{B} S_{B}}-W_{S_{A} S_{A} S_{B} S_{B}}\right)
$$

donde $W_{\text {R1R1,S2S2 }}$ y $W_{\text {S1S1,S2S2 }}$ representan los valores de fitness del insecto correspondientes a los genotipos $R_{A} R_{A}, S_{B} S_{B}$ (homocigota resistente para el alelo A y homocigota susceptible para el alelo B) y $\mathrm{S}_{A} \mathrm{~S}_{A}, \mathrm{~S}_{B} \mathrm{~S}_{B}$ (doble homocigoto susceptible), respectivamente, sobre un cultivo con dos toxinas acumuladas para la misma plaga blanco (Brévault et al., 2013). FLR varía desde 0, cuando no se cumple la letalidad redundante, hasta 1 cuando la letalidad redundante es completa. En efecto, en un cultivo que expresa ambas toxinas, si el fitness de los individuos resistentes a una de las dos toxinas es el mismo que el fitness de los insectos susceptibles a ambas, entonces se cumple el principio de letalidad redundante en su máxima expresión. Cualquier situación que incremente el fitness del genotipo resistente para una de las toxinas en relación al fitness del doble homocigoto susceptible $\left(W_{\text {RARA,SBSB }}>W_{\text {SASA,SBSB }}\right)$, provocará una disminución del FLR. Un factor que puede provocar tal efecto es la resistencia cruzada a la toxina B por selección con la toxina $A$. Otro factor es la disminución de la concentración de la toxina B, por ejemplo a través del desarrollo fenológico del cultivo, de tal manera que no resulta suficiente para provocar mortalidad (Onstad \& Gould, 1998; Alinia et al., 2000; Carrière et al., 2010; Brévault et al., 2013). A través de modelos de simulación incorporando cultivos con dos toxinas piramidadas, Brévault et al. (2013) identificaron una alta sensibilidad de la tasa de evolución de resistencia a la disminución del factor de letalidad redundante, especialmente cuando se asume herencia recesiva de la resistencia. Este tipo de estudios señala que los desvíos respecto a las condiciones ideales pueden ocasionar una importante reducción de los beneficios de esta opción de manejo de la resistencia.

La estrategia de piramidar eventos ofrece sus mejores perspectivas si se la implementa en forma proactiva (Zhao et al., 2005), pero si se la aplica cuando la resistencia a una de las toxinas ya ha surgido, parece perder sus mejores beneficios (Tabashnik et al., 2013). El uso de variedades con genes piramidados no exime de aplicar la estrategia AD-R; sin embargo, si se emplea correctamente, esta herramienta puede permitir la flexibilización de ciertos aspectos cuantitativos de la estrategia AD-R (Huang et al., 2011), por ejemplo la reducción del porcentaje de los lotes destinada a la siembra de refugios en maíz (20\% a 5\%) y algodón (50\% a 20\%) (Storer et al., 2012).

\section{LA EXPERIENCIA EN EL MUNDO}

La primera generación de cultivos Bt con incorporación de una sola toxina, comenzó a sembrarse comercialmente en 1996 (Bourguet et al., 2005; ISAAA, 2014). El primer exponente de la segunda generación de cultivos combinando dos genes Bt, fue algodón, aprobado en 2002 en Australia y EE.UU. (Zhao et al., 2005) y lanzado comercialmente en 2003 (Storer et al., 2012). En el caso del cultivo de maíz, los primeros materiales con dos genes piramidados recibieron aprobación completa en EE.UU. en 2010 (Ghimire et al., 2011). Los reportes de la implementación exitosa de cultivos Bt son numerosos y no es objetivo de esta revisión recorrerlos exhaustivamente; no obstante, a modo de ejemplo, uno de los casos más relevantes es el de Ostrinia nubilalis (Marquardt et al., 2013) y P. gossypiella (Tabashnik et al., 2005). A pesar del publicitado éxito de la adopción masiva de cultivos Bt en diferentes países del mundo, desde principios del corriente siglo comenzaron a detectarse casos de fallas de control de plagas blanco a determinados cultivos Bt. Las diferencias de criterios en la definición de resistencia dieron como resultados diferentes descripciones de la evolución temporal de este problema, como se ilustra en la Figura 4, sobre la base de las contribuciones de Gouws (2011) y Tabashnik et al. (2013). La descripción de Gouws (2011) descansa en un criterio para definir resistencia, que resulta menos exigente que el empleado por Tabashnik et al. (2013), lo que explica el mayor número de casos incluidos en la descripción del primero (Fig. 4). Sin embargo, asumiendo que la proporción de individuos resistentes en la población aumenta en forma sostenida, a menos que se implementen medidas de mitigación en una fase muy temprana de la evolución de resistencia a campo, cabe esperar que un bajo porcentaje de individuos resistentes en la población, en pocos años se traduzca en un porcentaje mayor, con fallas de control.

De acuerdo a la revisión de Tabashnik et al. (2013), de las 13 especies de plaga blanco más relevantes de los cultivos Bt adoptados en todo el mundo desde 1996, siguiendo el criterio de aumento de frecuencia de alelos de resistencia a campo y daños económicos, se ha detectado resistencia en algunas poblaciones de 5 especies ( 3 de maíz y 2 de algodón). La tasa de detección de resistencia se incrementó desde 2006, probablemente como consecuencia del incremento del área sembrada con cultivos $\mathrm{Bt}$, el aumento del número de poblaciones expuestas, la exposición acumulada de las plagas a la toxina Bt y la mayor atención asignada a los programas de monitoreo de la resistencia. 


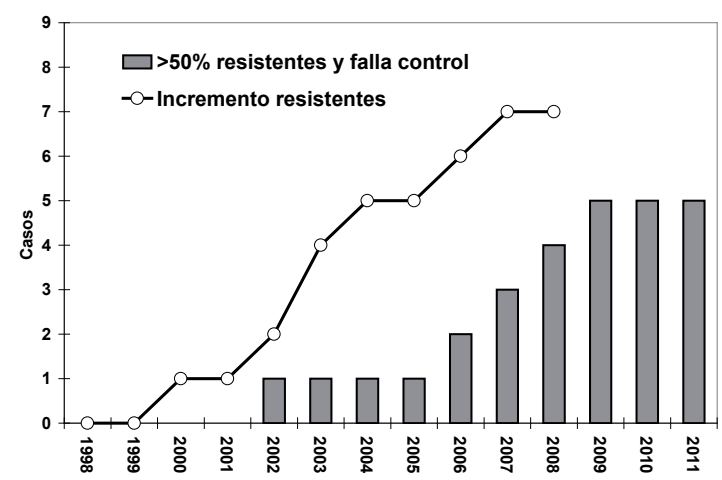

Figura 4. Acumulación temporal de casos de resistencia de insectos a cultivos $\mathrm{Bt}$ a nivel mundial según dos definiciones de resistencia. La línea continua corresponde a casos de resistencia definida como incremento significativo de la proporción de individuos resistentes en la población (Gouws, 2011). Las barras representan los casos en los que se identificó un incremento de los individuos susceptibles a más del $50 \%$ de la población junto a las consecuentes fallas de control (Tabashnik et al., 2013).

Diversos autores destacan el éxito de los cultivos Bt sobre la base de la extensión mundial de la adopción de cultivos Bt, los 18 años de historia que esta tecnología lleva acumulados, su alta performance en el control de las plagas blanco con una percepción de altos beneficios, la supresión regional de la plaga blanco y la relativamente baja proporción de casos de resistencia constatados (Carrière et al., 2010; Hutchison et al., 2010; Huang et al., 2011; Downes \& Mahon, 2012). Respecto a este último aspecto, la experiencia reunida hasta el presente constituye un respaldo empírico a la estrategia AD-R y la teoría subyacente. La revisión de todos los casos de adopción de cultivos Bt, exitosos y no exitosos, en general confirman las predicciones que se desprenden de la teoría, a pesar de que las evidencias empíricas de campo son aún limitadas (Tabashnik et al., 2008, 2009). En efecto, la persistencia de la susceptibilidad de plagas blanco a los eventos Bt introducidos en cultivos, se asocia al cumplimiento del requisito de alta dosis, bajas frecuencias iniciales de alelos de resistencia (con anterioridad a la introducción del cultivo Bt) y cumplimiento de la implementación de áreas refugio. Los casos de aparición de incremento del porcentaje de individuos resistentes y/o fallas de control, se han asociado al incumplimiento de uno o más de estos supuestos (Tabashnik et al., 2008; Huang et al., 2011; Tabashnik et al., 2013), incluso la identificación de costos adaptativos y resistencia incompleta (Carrière et al., 2006) como el caso de Pectinophora gossypiella en algodón (Tabashnik et al., 2012).

\section{LA SITUACIÓN EN LA ARGENTINA}

En la Argentina, la historia de los cultivos transgénicos con propiedades insecticidas comienza en 1998 con la aprobación de los eventos BT176 de Syngenta y MON810 de Monsanto, mediante las Resoluciones SAGPyA 19/98 y SAGPyA N 429/98 (MAGyP, 2014). El primer cultivo con eventos piramidados fue el maíz, con la aprobación en 2010 del evento MON89034, acumulando las toxinas Cry1A.105 y Cry2Ab2, mediante la Resolución SAPyA N 641 (MAGyP, 2014). Ese mismo año se aprobó el evento MON89034 x MON88017, sumando a las dos toxinas anteriores, la proteína específica para larvas de coleópteros, Cry3Bb, mediante Resolución SAPyA № 640/10 (MAGyP, 2014). Hasta el presente se aprobaron para su comercialización, 16 eventos o combinaciones de eventos Bt, 1 en algodón, 1 en soja y 14 en maíz (MAGyP, 2014).

En la provincia de San Luis, Argentina, en la campaña 2012/13 se detectaron daños no esperados de Diatraea saccharalis en maíces Bt portadores de tres diferentes toxinas (Cry2Ab2, Cry1A.105 y Cry1F). Si bien aún resta confirmar técnicamente el estatus de resistencia, el "caso San Luis" dispara preguntas respecto a cuáles de los supuestos o requisitos de la estrategia AD-R pueden no haberse cumplido. Entre las hipótesis esgrimidas, se señala que las características ambientales especiales del norte de San Luis pueden haber contribuido a través de un inusitado nivel de densidad poblacional y alto número de generaciones de la plaga. Esta hipótesis es consistente con la sospecha de que efectivamente las fallas inesperadas de control fueron ocasionadas por evolución de resistencia a campo. Si esto se confirma, la repentina aparición de muy altos niveles de daño de $D$. saccharalis en tan solo unos pocos años de presencia de los híbridos Herculex I y VT3Pro, portadores de los tres eventos que evidenciaron daños no esperados, sugiere enfocar la atención sobre un subconjunto de las bases de la estrategia AD-R. En efecto, la teoría predice que una baja frecuencia inicial de alelos de resistencia, un elevado tamaño efectivo de los refugios, un mínimo nivel de dominancia de la resistencia y una elevada concentración de la toxina Bt en la planta que determine alta dosis para una determinada plaga blanco, contribuyen a minimizar la tasa de evolución de resistencia. El peso relativo de estos factores no es homogéneo y probablemente la velocidad de adaptación sea más sensible al tamaño del refugio efectivo y al nivel de dominancia del alelo de resistencia. Así, éstas constituyen las preguntas más relevantes para dilucidar las causas de los daños no esperados en el "caso San Luis". 
Durante las campañas agrícolas 2012/13 y 2013/14, diversos reportes tanto del sector público como del sector privado, señalan que en algunas provincias se han detectado niveles inesperados de daños provocados por Spodoptera frugiperda en diferentes híbridos de maíz. Las principales zonas involucradas se encuentran en las provincias del Litoral, Chaco, Santiago del Estero, Salta y este de Córdoba. En ensayos de laboratorio y de campo, Flores \& Balbi (2014) encontraron hasta $15 \%$ de supervivencia de larvas de $S$. frugiperda en híbridos de maíz Bt con la toxina Bt específica Cry1Fa. Estos primeros informes de fallas de control de esta plaga en maíces Bt motivan la indagación de los factores que pueden estar asociados, incluyendo la confirmación de evolución de resistencia, a fin de diseñar un plan de mitigación.

Por otra parte, ante la sospecha de que entre las causas se encuentra involucrado un bajo nivel de adopción del refugio, ha ganado espacio el debate respecto a la conveniencia de implementar el refugio integrado consistente en la siembra de mezcla semilla de maíz Bt y convencional. El principal factor señalado como desventaja de un refugio integrado es la movilidad de las larvas entre plantas Bt y convencionales (Andow, 2008; Storer et al., 2012), por los siguientes argumentos: a) el movimiento de larvas homocigotas susceptibles desde plantas convencionales hacia plantas $\mathrm{Bt}$, reduce el tamaño efectivo del refugio; b) las larvas neonatas portadoras de un alelo resistente pero fenotípicamente susceptibles por la alta dosis, pueden sobrevivir el tiempo suficiente sobre las plantas Bt como para dispersarse a una planta refugio en la que puede completar el desarrollo. Al ocurrir esto, se considera que los individuos heterocigotas se convierten en funcionalmente resistentes, y la evolución de resistencia se ve acelerada considerablemente. Otro aspecto es la preferencia de oviposición de las hembras: la preferencia encontrada en hembras de Spodoptera frugiperda para desovar en plantas de maíz Bt debido a su estado sanitario (Téllez-Rodríguez et al., 2014), puede acentuarse cuando ambas plantas se encuentran en mayor proximidad, como es el caso de un refugio en mezcla, generando como consecuencia una disminución funcional del tamaño efectivo del refugio.

Entre las posibles desventajas de implementar el refugio integrado, en el caso específico de algodón transgénico con toxinas piramidazas, se ha puntualizado que el flujo génico que ocurriría entre algodón Bt y algodón convencional en un refugio integrado, provocaría la disminución del nivel de letalidad redundante, contribuyendo a acelerar la tasa de evolución de resistencia en comparación con refugios estructurados (Showalter et al., 2012).

El balance de la opinión de expertos mundiales parece seguir favoreciendo la opción de un refugio estructurado (Onstad et al., 2011; Carroll et al., 2012; Storer et al., 2012; Wangila et al., 2013, entre otros). La escasez de información científica sobre aspectos de la bioecología de la plaga blanco que resultan clave para un análisis de riesgo sólido, no permite respaldar un cambio de táctica para el manejo de la resistencia de $D$. saccharalis. Para el caso de $S$. frugiperda, las perspectivas de contribución de refugios integrados para el manejo la resistencia serían aún menos alentadoras debido a la gran movilidad de las larvas. Si bien recientemente se ha autorizado oficialmente (INASE, 2014) la comercialización de mezclas de dos híbridos de maíz en semilla de clase fiscalizada, el aporte de nueva información y análisis más profundos podría fundamentar una revisión de esta decisión.

\section{COMENTARIOS FINALES}

Ante la gran capacidad de adaptación que los artrópodos evidencian, es indispensable diseñar estrategias de manejo de resistencia a cultivos Bt sobre la base del conocimiento, tanto de la biología de la plaga blanco como de las características de la variedad Bt involucrada. La estrategia AD-R ha demostrado su robustez, y su complementación con el uso de combinaciones de genes que codifican la síntesis de dos o más toxinas con diferentes sitios de acción, ofrece perspectivas promisorias. Sin embargo, la incertidumbre sobre algunos factores clave en el cambio de frecuencia de alelos resistentes, sumada al incumplimiento de los supuestos de la estrategia AD-R, dificultan el manejo de la resistencia de plagas. La corrección de estas falencias y el anclaje consecuente de las decisiones regulatorias, constituyen los desafíos para la República Argentina. En el diseño de una sólida estrategia de manejo de la resistencia de plagas a cultivos Bt, se deberían considerar un conjunto de aspectos, incluyendo la bio-ecología de la plaga, las propiedades de las toxinas Bt, los patrones espaciales y geográficos de adopción de los cultivos $\mathrm{Bt}$, el monitoreo de la susceptibilidad de las plagas blanco, y la comunicación fluida entre agricultores, extensionistas y profesionales de la industria y el sector público (Macintosh, 2009). No obstante, como corolario de esta revisión, es oportuno señalar que los problemas de resistencia de plagas surgen, en primera instancia, como consecuencia de la reducción del manejo de plagas a esquemas de control apoyados en una única herramienta. 


\section{AGRADECIMIENTOS}

Esta revisión se enmarca en los proyectos PNPV 11305032, PNPV 1135031, CORDO-1262205 y CORDO-1262206 del Instituto Nacional de Tecnología Agropecuaria.

\section{BIBLIOGRAFÍA}

Alinia, F.; L. Rubia and J. Bennett, 2000. Effect of plant age, larval age, and fertilizer treatment on resistance of a cry1Ab-transformed aromatic rice to lepidopterous stem borers, 484-493.

Andow, D.A., 2008. The risk of resistance evolution in insects to transgenic insecticidal crops. Collection of Biosafety Reviews 4:142-99.

ArgenBio, 2014. Evolución de la superficie cultivada con OGM <http://www.argenbio.org/adc/uploads/imagenes_doc/planta_stransgenicas/5_Tabla_de_evolucion_de_sup_sembradeas_con_OGM_en_Arg_en_ has.pdf>. Consultada el 15/10/2014.

Bates, S.L.; J.Z. Zhao, R.T. Roush and A.M. Shelton, 2005. Insect resistance management in GM crops: past, present and future. Nature Biotechnology 23:57-62.

Bernardi, O.; G.S. Malvestiti, P.M. Dourado, W.S. Oliveira, S. Martinelli, G.U. Berger, G.P. Head and C. Omoto, 2012. Assessment of the high-dose concept and level of control provided by MON $87701 \times$ MON 89788 soybean against Anticarsia gemmatalis and Pseudoplusia includens (Lepidoptera: Noctuidae) in Brazil. Pest Management Science 68:1083-1091.

Bourguet, D. and M. Raymond, 1998. The molecular basis of dominance relationships: the case of some recent adaptive genes. Journal of Evolutionary Biology 11:103-122.

Bourguet, D. and A. Genissel, 2000. Insecticide resistance and dominance levels. Journal of Economic Entomology 93:1588-1595.

Bourguet, D.; M. Desquilbet and S. Lemarié, 2005. Regulating insect resistance management: the case of nonBt corn refuges in the US. Journal of Environmental Management 76:210-20.

Bravo, A.; I. Gómez, H. Porta, B.I. García-Gómez, C. Rodriguez-Almazan, L. Pardo and M. Soberón, 2012. Evolution of Bacillus thuringiensis Cry toxins insecticidal activity. Microbial Biotechnology 6:17-26.

Brévault, T.; S. Heuberger, M. Zhang, C. Ellers-Kirk, X. $\mathrm{Ni}$, L. Masson and X. Li, 2013. Potential shortfall of pyramided transgenic cotton for insect resistance management. Proceedings of the National Academy of Science 110:5806-5811.

Campagne, P.; M. Kruger, R. Pasquet, B. Le Ru, J. Van den Berg, 2013. Dominant inheritance of field-evolved resistance to Bt corn in Busseola fusca. PloS ONE, 8(7):e69675.

Caprio, M.A.; N. Storer, M.S. Sisterson, S. Peck, M. De Holanda Nunes, 2008. Assessing the risk of the evolution of resistance to pesticides using spatially complex simulation models. En M.E. Whalon; D. Mota-Sanchez and R.M. Hollingworth (Eds.): Global pesticide resistance in arthropods. CAB International, pp. 90-117.

Carrière Y., C. Ellers-Kirk, R.W. Biggs, M.E. Nyboer, G.C. Unnithan, T.J. Dennehy and B.E. Tabashnik, 2006. Cadherin-based resistance to Bt cotton in hybrid strains of pink bollworm: fitness costs and incomplete resistance. Journal of Economic Entomology 99:1925-35.

Carrière, Y., D.W. Crowder and B.E. Tabashnik, 2010. Evolutionary ecology of insect adaptation to Bt crops. Evolutionary Applications 3:561-573.

Carroll, M.W.; G. Head and M. Caprio, 2012. When and where a seed mix refuge makes sense for managing insect resistance to Bt plants. Crop Protection 38:74-9.

Crava C.M., G.P. Farinós, Y. Bel, P. Castañera, B. Escriche, 2013. Quantitative genetic analysis of Cry1Ab tolerance in Ostrinia nubilalis Spanish populations. Journal of Invertebrate Pathology 113:220-227.

Downes, S. and R. Mahon, 2012. Successes and challenges of managing resistance in Helicoverpa armigera to Bt cotton in Australia. GM Crops and Food: Biotechnology in Agriculture and the Food Chain 3:228-234.

FAO, 2014. AGP Integrated Pest Management. <http:// www.fao.org/agriculture/crops/thematic-sitemap/theme/pests/ipm/en/>. Consultada el 9 de septiembre de 2014.

Ferré, J. and J. Van Rie, 2002. Biochemistry and genetics of insect resistance to Bacillus thuringiensis. Annual Review of Entomology 47:501-33.

Ferré, J.; J. Van Rie and S.C. Macintosh, 2008. Insecticidal genetically modified crops and insect resistance management (IRM). En J. Romeis; A.M. Shelton and G.G. Kennedy (Eds.): Integration of insect-resistant genetically modified crops within IPM Programs. Springer, pp. 41-85.

Fitt, G.P.; C. Omoto, A.H. Maia, J.M. Waquil, M. Caprio, M.A. Okech, E. Cia, Nguyen, Huu Huan and D.A. Andow, 2006. Resistance risks of Bt cotton and their management in Brazil. En A. Hilbeck; D.A. Andow and E.M. Fontes (Eds.): Environmental risk assessment of genetically modified organisms. Volumen 2: Methodologies for assessing Bt cotton in Brazil. Cabi Publishing, pp. 300-345.

Flores, F. y E. Balbi, 2014. Evaluación del daño de oruga militar (Spodoptera frugiperda) en diferentes híbridos comerciales de maíz transgénico. Maíz Actualización 2014. Informe de actualización Técnica № 31, pp. 2328. 
George, Z. and N. Crickmore, 2012. Bacillus thuringiensis Applications in Agriculture. En E. Sansinenea (Ed.): Bacillus thuringiensis Biotechnology. Springer, pp. 19-39.

Ghimire, M.N.; F. Huang, R. Leonard, G.P. Head and Y. Yang, 2011. Susceptibility of Cry1Ab-susceptible and -resistant sugarcane borer to transgenic corn plants containing single or pyramided Bacillus thuringiensis genes. Crop Protection 30:74-81.

Gómez, I.; J. Sánchez, C. Muñoz-Garay, V. Matus, S.S. Gill, M. Soberón and A. Bravo, 2014. Bacillus thuringiensis Cry1A toxins are versatile proteins with multiple modes of action: two distinct pre-pores are involved in toxicity. Biochemestry Journal 459:383-396.

Gould, F., 1986. Simulation models for predicting durability of insect-resitant germ plasm: A deterministic diploid, two-locus model. Environmental Entomology 15:1-10.

Gould, F., 1998. Sustainability of transgenic insecticidal cultivars: integrating pest genetics and ecology. Annual Review of Entomology 43:701-26.

Gouws, M., 2011. The refuge concept in insect resistance management: its history and future application in South Africa. M.Sc. Dissertation North-West University, Potchefstroom Campus, pp. 182.

Groeters, F.R. and B.E. Tabashnik, 2000. Roles of selection intensity, major genes, and minor genes in evolution of insecticide resistance. Journal of Economic Entomology 93:1580-1587.

Han, L.; C. Han, Z. Liu, F. Chen and J. Luis, 2014. Binding site concentration explains the differential susceptibility of Chilo suppressalis and Sesamia inferens to Cry1A-producing rice. Applied and Environmental Microbiology 80:5134-5140.

Head, G.P. and J. Greenplate, 2012. The design and implementation of insect resistance management programs for Bt crops. GM Crops and Food: Biotechnology in Agriculture and the Food Chain 3:144-53.

Heckel, D.G., 2012. Insecticide resistance after Silent Spring. Science 337:1612-1614.

Heckel, D.G.; L.J. Gahan, S.W. Baxter, J.-Z. Zhao, A.M. Shelton, F. Gould and B.E. Tabashnik, 2007. The diversity of Bt resistance genes in species of Lepidoptera. Journal of invertebrate pathology 95:192-197.

Hernández-Rodríguez, C.S.; P. Hernández-Martínez, J. Van Rie, B. Escriche and J. Ferré, 2013. Shared midgut binding sites for Cry1A.105, Cry1Aa, Cry1Ab, Cry1Ac and Cry1Fa proteins from Bacillus thuringiensis in two important corn pests, Ostrinia nubilalis and Spodoptera frugiperda. PloS one, 8(7):e68164.

Huang F.; L.L. Buschman and R.A. Higgins, 1999. Susceptibility of different instars of European corn borer (Lepidoptera: Crambidae) to Bacillus thuringiensis. Journal of Economic Entomology 92:547-550.
Huang, F.; L.L. Buschman, R.A. Higgins and H. Li, 2002. Survival of Kansas Dipel resistant European corn borer (Lepidoptera: Crambidae) on Bt and non-Bt corn hybrids. Journal of Economic Entomology 95:614-621.

Huang, F.; B.R. Leonard and R.H. Gable, 2006. Comparative susceptibility of European corn borer, southwestern corn borer, and sugarcane borer (Lepidoptera: Crambidae) to Cry1Ab protein in a comercial Bacillus thuringiensis corn hybrid. Journal of Economic Entomology 99:194-202.

Huang, F.; D. Andow and L.L. Buschman, 2011. Success of the high-dose/refuge resistance management strategy after 15 years of Bt crop use in North America. Entomologia Experimentalis et Applicta 140:1-16.

Hutchinson, W. D.; E.C. Burkness, P.D. Mitchell, R.D. Moon, T.W. Leslie, S.J. Fleischer, M. Abrahamson, K.L. Hamilton, K.L. Steffey, M.E. Gray, R.L. Hellmich, L.V. Kaster, T.E. Hunt, R.J. Wright, K. Pecinovsky, T.L. Rabaey, B.R. Flood and E.S. Raun, 2010. Areawide Suppression of European Corn Borer with Bt Maize Reaps Savings to Non-Bt Maize Growers. Science 330:222-225

INASE (Instituto Nacional de Semillas), 2014. Resolución $\quad N^{\circ}$ 112/14. <http://www.inase.gov.ar/index. php?option $=$ com_remository \& temid $=102 \&$ func $=$ s elect\&id $=11 \&$ orderby $=2 \&$ page $=24>$ Consultada el $10 / 12 / 2014$

ISAAA, 2014. Biotech crops adoption in 2013. <http:// Www.isaaa.org/resources/biotechinfomercials/ brief46-2013/default.asp> Consultada el 5/05/2014.

Ives, A.R.; P.R. Glaum, N.L. Ziebarth and D.A. Andow, 2011. The evolution of resistance to two-toxin pyramid transgenic crops. Ecological Applications 21:503-515.

Jackson, R.E.; M.A. Marcus, F. Gould, J.R. Bradley Jr. and J.W. Van Duyn, 2007. Cross-resistance responses of Cry1Ac selected Heliothis virescens (Lepidoptera: Noctuidae) to the Bacillus thuringiensis protein Vip3A. Journal of Economic Entomology 100:180-186.

Jurat-Fuentes, J.L.; L. Karumbaiah, S.R.K. Jakka, C. Ning and C. Liu, 2011. Reduced levels of membrane-bound alkaline phosphatase are common to lepidopteran strains resistant to Cry Toxins from Bacillus thuringiensis. PLoS ONE 6:e17606.

Kang J.; F. Huang and D.W. Onstad, 2014. Modeling evolution of resistance of sugarcane borer (Lepidoptera: Crambidae) to transgenic Bt corn. Environmental Entomology 43:1084-1104.

Kogan, M., 1998. Integrated pest management: Historical perspectives and contemporary developments. Annual Review of Entomology 43:243-270.

Maclntosh, S.C., 2012. Managing the risk of insect resistance to transgenic insect control traits: practical approaches in local environments. Pest Management Science 66:100-6. 
MacNair, M.R., 1991. Why the evolution of resistance to anthropogenic toxins normally involves major gene changes: the limits to natural selection. Genetica 84, 213-219.

Manyangarirwa, W.; M. Turnbull, G.S. McCutcheon and J.P. Smith, 2006. Gene pyramiding as a Bt resistance management strategy: How sustainable is this strategy? African Journal of Biotechnology 5:781-785.

Marquardt, P.T.; C.H. Krupke, J.J. Camberato and W.G. Johnson. 2013. The effect of nitrogen rate on transgenic corn Cry3Bb1 protein expresión. Pest Management Science 70:763-770.

McCallum, H., 2000. Population parameters: Estimation for ecological models. Blackwell Science Ltd., pp. 348.

McKenzie, J.A. and P. Batterham, 1994. The genetic, molecular and phenotypic consequences of selection for insecticide resistance. Trends in Ecology and Evolution 9:166-169.

MAGyP, 2014. OGM Comerciales. <http://www.minagri. gob.ar/site/agregado_de_valor/biotecnologia/55OGM_COMERCIALES/index.php>. Consultada el 16/10/2014.

Mitchell, P.D. and W.D. Hutchison, 2009. Decision making and economic risk in IPM. In Radcliffe, E. B.; W.D. Hutchison and R.E. Cancelado (Eds.): Integrated pest management. Cambrige University Press, pp.33-50.

Nair, R.; V. Kalia, K.K. Aggarwal and G.T. Gujar, 2010. Inheritance of Cry1Ac resistance and associated biological traits in the cotton bollworm, Helicoverpa armigera (Lepidoptera: Noctuidae). Journal of Invertebrate Pathology 104:31-38.

Nelson, M.E. and A.P. Alves, 2014. Plant incorporated protectants and insect resistance. In Onstad, D. (Ed.): Insect resistance management. Biology, economics, and prediction. Second edition. Elsevier, Pp. 99-147.

Olsen, K.M., J.C. Daly, H.E. Holt and E.J. Finnegan, 2005. Season-long variation in expression of Cry1Ac gene and efficacy of Bacillus thuringiensis toxin in transgenic cotton against Helicoverpa armigera (Lepidoptera: Noctuidae). Journal of Economic Entomology 98:1007-1017

Onstad, D., 2014a. Major issues in insect resistance management. In Onstad, D.W. (Ed.): Insect resistance management. Biology economics and prediction. Academic Press, pp. 1-24.

Onstad, D. 2014b. Modelling for prediction and management. In Onstad, D.W. (Ed.): Insect resistance management. Biology economics and prediction. Academic Press, pp. 453-483.

Onstad, D.W. and F. Gould, 1998. Do dynamics of crop maturation and herbivorous insect life cycle influence the risk of adaptation to toxins in transgenic host plants? Environmental Entomology 27:517-522

Onstad, D. and A. Gassmann, 2014. Concepts and complexities of population genetics. In: Onstad, D.W. (Ed.): Insect resistance management. Biology economics and prediction. Academic Press, pp. 149-183.

Onstad, D.W.; P.D. Mitchell, T.M. Hurley, J.G. Lundgren, R.P. Porter, C.H. Krupke, J.L. Spencer, C.D. DiFonzo, T.S. Baute, R.L. Hellmich, L.L. Buschman, W.D. Hutchison and J.F. Tooker, 2011. Seeds of change: Corn seed mixtures for resistance management and integrated pest management. Journal of Economic Entomology 104:343-52.

Palma, L.; C.S. Hernández-Rodríguez, M. Maeztu, P. Hernández-Martínez, I. Ruiz de Escudero, B. Escriche, D. Muñoz, J. Van Rie, J. Ferré and P. Caballero, 2012. Vip3C, a novel class of vegetative insecticidal proteins from Bacillus thuringiensis. Applied and Environmental Microbiology 78:7163-7165.

Pardo-López, L.; M. Soberón and A. Bravo, 2013. BaciIlus thuringiensis insecticidal three-domain Cry toxins: mode of action, insect resistance and consequences for crop protection. FEMS microbiology reviews 37:322.

Peshin, R. and A.K. Dhawan (Eds.), 2009. Integrated Pest Management: Innovation-development process. Springer, New York, 690 pp.

Peshin, R. and W.J. Zhang, 2014. Integrated Pest Management and Pesticide Use. In Pimentel, D. and R. Peshin (Eds.): Integrated Pest Management. Pesticide Problems Vol. 3, pp. 1-46.

Pigott, C.R. and D. Ellar, 2007. Role of Receptors in Bacillus thuringiensis crystal toxin activity. Microbiology and Molecular Biology Reviews 71:255-281.

Pigott, C.R.; M.S. King and D.J. Ellar, 2008. Investigating the properties of Bacillus thuringiensis Cry proteins with novel loop replacements created using combinatorial molecular biology. Applied and Environmental Microbiology 74:3497-3511.

Prato, M.; A. Khadjavi, G. Mandili, V.G. Minero and G. Giribaldi, 2012. Insecticides as strategic weapons for malaria vector control. In Perveen, F. (Ed.): Insecticides - Advances in Integrated Pest Management. InTech:91-114

REX Consortium, 2010. The skill and style to model the evolution of resistance to pesticides and drugs. Evolutionary Applications 3:375-390.

Roush, R.T., 1994. Managing pests and their resistance to Bacillus thuringiensis: Can transgenic crops be better than sprays? Biocontrol Science and Technology 4:501-516.

Roush, RT., 1998. Two-toxin strategies for management of insecticidal transgenic crops: can pyramiding succeed where pesticide mixtures have not? Philosophi- 
cal Transactions of the Royal Society of London B 353:1777-1786.

Roush, R.T. and J.A. McKenzie, 1987. Ecological genetics of insecticide and acaricide resistance. Annual Review of Entomology 32:361-380.

Roush, R.T. and J.C. Daly, 1990. The role of population genetics in resistance research and management. In Roush, R.T. and B.E. Tabashnik (Eds.): Pesticide resistance in arthropods. Chapman and Hall, pp. 97-152.

Ruiz de Escudero, I.; N. Banyuls, Y. Bel, M. Maeztu, B. Escriche, D. Muñoz, P. Caballero and J. Ferré, 2014. A screening of five Bacillus thuringiensis Vip3A proteins for their activity against lepidopteran pests. Journal of Invertebrate Pathology 117: 51-55.

Showalter, A. M.; S. Heuberger, B.E. Tabashnik, Y. Carrière and B. Coates, 2009. A primer for using transgenic insecticidal cotton in developing countries. Journal of insect science (Online) 9:22.

Siegfried, B.D.; M. Rangasamy, H. Wang, T. Spencer, C.V. Haridas, B. Tenhumberg, D.V. Sumerford and N.P. Storer, 2014. Estimating the frequency of Cry1F resistance in field populations of the European corn borer (Lepidoptera: Crambidae). Pest Management Science 70:725-33.

Stern, V. M.; R.F. Smith, R. van den Bosch and K. S. Hagen, 1959. The integrated control concept. Hilgardia 29:89-101.

Storer, N.P.; G.D. Thompson and G.P. Head, 2012. Application of pyramided traits against Lepidoptera in insect resistance management for Bt crops. GM Crops and Food: Biotechnology in Agriculture and the Food Chain 3:154-162.

Tabashnik, B.E.; Y-B. Liu, T. Malvar, D.G. Heckel, L. Masson and J. Ferré, 1998. Insect resistance to Bacillus thuringiensis: Uniform or diverse? Philosophical Transaction of the Royal Society of London B 353:17511756.

Tabashnik, B.E.; F. Gould and Y. Carrière, 2004. Delaying evolution of insect resistance to transgenic crops by decreasing dominance and heritability. Journal of Evolutionary Biology 17:904-12.

Tabashnik, B.E.; T.J. Dennehy and Y. Carrière, 2005. Delayed resistance to transgenic cotton in pink bollworm. Proceedings of the National Academy of Science 102:15389-15393.

Tabashnik, B.E.; A.J. Gassmann, D.W. Crowder and Y. Carriére, 2008. Insect resistance to Bt crops: Evidence versus theory. Nature Biotechnology 26:199-202.

Tabashnik, B.E.; J.B.J. Van Rensburg and Y. Carrière, 2009. Field-evolved insect resistance to Bt crops: Definition, theory, and data. Journal of Economic Entomology 102:2011-2025.

Tabashnik, B.; S. Morin, G.C. Unnithan, A.J. Yelich, S. Har- pold, M.S. Sisterson, P.C. Ellsworth, T.J. Dennehy, L. Antilla, L. Liesner, M. Whitlow, R.T. Staten, J.A. Fabrick, $X$. Li and Y. Carrière, 2012. Sustained susceptibility of pink bollworm to Bt cotton in the United States, GM Crops and Food: Biotechnology in Agriculture and the Food Chain 3:194-200.

Tabashnik, B.E.; T. Brévault and Y. Carrière, 2013. Insect resistance to $\mathrm{Bt}$ crops: Lessons from the first billion acres. Nature Biotechnology 31:510-21.

Tabashnik, B.E.; D. Mota-Sánchez, M.E. Whalon, R.M. Hollingworth and Y. Carrière, 2014. Defining terms for proactive management of resistance to Bt crops and pesticides. Journal of Economic Entomology 107: 496-507.

Téllez-Rodríguez, P.; B. Raymond, I. Morán-Bertot, L. Rodríguez-Cabrera, D.J. Wright, C.G. Borroto, C. AyraPardo, 2014. Strong oviposition preference for Bt over non-Bt maize in Spodoptera frugiperda and its implications for the evolution of resistance. BMC Biology $12: 48$.

Trumper, E.V., 2009. Toma de decisiones en el manejo artrópodos plaga. Revisión de enfoques, métodos y conceptos. Actas de las XIII Jornadas Fitosanitarias Argentinas, Termas de Río Hondo, 30 de septiembre-2 de octubre 2009.

USEPA, 2013. Plant incorporated protectants. <www.epa. gov/pesticides/biopesticides/pips/> Consultada el 12/09/2014.

van Frankenhuyzen, K., 2009. Insecticidal activity of BaciIlus thuringiensis crystal proteins. Journal of Invetebrate Pathology 101:1-16.

Wangila, D.S.; B.R. Leonard, M.N. Ghimire, Y. Bai, L. Zhang, Y. Yang, K.D. Emfinger, G.P. Head, F. Yang, Y. Niu and F. Huang, 2013. Occurrence and larval movement of Diatraea saccharalis (Lepidoptera: Crambidae) in seed mixes of non-Bt and Bt pyramid corn. Pest Management Science 69:1163-72.

Whalon, M.E.; D. Mota-Sánchez and R.M. Hollingworth, 2013. Arthropod pesticide resistance database. <http://www.pesticideresistance.com/index.php> Consultada el 15/10/2014

Yu, X.; A. Zheng, S. Wang, S. Li, J. Zhu, L. Wang, H. Liu, Q. Deng and P. Li, 2011. Characterization of vegetative insecticidal protein Vip genes of Bacillus thuringiensis from Sichuan Basin in China. Current Microbiology 62:752-757.

Zhao, J.Z.; J. Cao, H.L. Collins, S.L. Bates, R.T. Roush, E.D. Earle and A.M. Shelton, 2005. Concurrent use of transgenic plants expressing a single and two Bacillus thuringiensis genes speeds insect adaptation to pyramided plants. Proceedings of the National Academy of Science 102:8426-8430. 